\title{
Analysis of the Relationships for the Vibrational Response to the Excitation of Vibro-acoustic Processes in Conductors from the Action of a Pulsed Current
}

\section{O. A. Troickij¹, 0. B. Skvorcov,1,2 E. A. Pravotorova1, and V. I. Stashenko}

${ }^{1}$ Mechanical Engineering Research Institute of the Russian Academy of Sciences (IMASH RAN), 4, M. Kharitonyevskiy Pereulok, 101990 Moscow, Russia

2"Scientific and Technical Center "Zavod Balansirovochnykh mashin", Varshavskoye shosse, 46, Moscow, 115230, Russia

\section{Abstract}

Evaluation of the mechanisms of formation of mechanical deformations is of great importance for the practical application of the electroplastic effect. Estimations of the efficiency of conversion of the energy of the electric pulse in the energy of the

Corresponding Author:

0. A. Troickij

oatroitsky@rambler.ru

Received: 21 December 2017

Accepted: 15 April 2018

Published: 6 May 2018

Publishing services provided by Knowledge E

(c) 0. A. Troickij et al. This article is distributed under the terms of the Creative Commons

Attribution License, which permits unrestricted use and redistribution provided that the original author and source are credited.

Selection and Peer-review under the responsibility of the MIE-2017 Conference Committee. magnetic field and mechanical oscillations are obtained.

Keywords: pulse current, metal, vibroacoustic, magnetic field, vibration sensors.

\section{INTRODUCTION}

The mechanisms of manifestation of the electroplastic effect (EPE), depending on the experimental conditions, can show the predominant role of various phenomena: the pinch effect [1], deformations associated with phase transitions [2], magnetohydrodynamic disturbances [3] and a large number of other processes [4, 5]. The mechanisms of the influence of electric fields on plastic deformation are still not fully understood [3-5]. In [5], for example, it is stated that "the mechanism of the electroplastic effect is the amplification of a weak external signal by fluctuations in a nonlinear system." This is confirmed by the large range of energy conversion efficiency (from $0.05 \%$ to $35 \%)$ in these processes.

\section{METHODS OF RESEARCH}

When conducting the research was carried out the measurement of vibration response of a multicomponent acceleration sensors that were glued to the round specimens of different metals [6]. Similarly conducted control the vibration response of specimens 


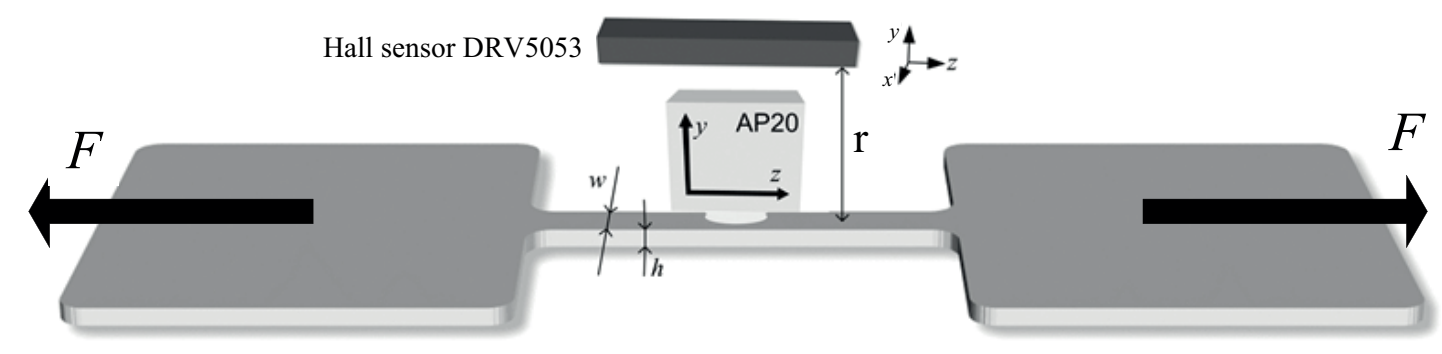

Figure 1: The location of vibration sensors and magnetic field relative to the sample of metal with a rectangular cross section.

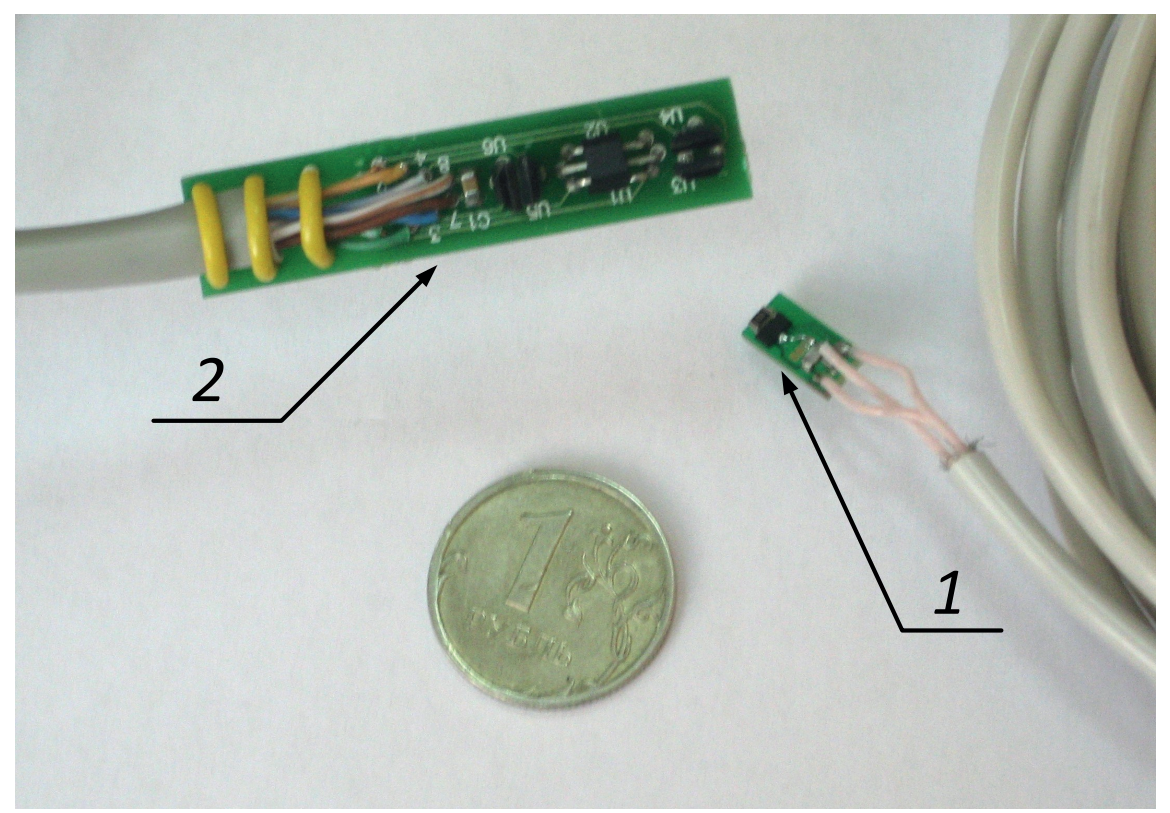

Figure 2: One-component magnetic field sensor on the chip MLX90242 and three-component magnetic field sensor on the chip DRV 5053.

with rectangular cross section, as shown in Figure 1. The mount of the piezoelectric accelerometer to the sample was performed with cyacrylic glue through the insulating spacer on the sensor. Control of the pulse current flowing through the sample was performed contactless Hall sensors, as shown in Figure 2. To improve the noise immunity of transmission of signals and measuring magnetic induction was performed using differential measurement schemes [7].

\section{RESULTS}

Typical vibration signals shown in Figure 3. Encountered in the sample by passing current pulse mechanical vibrations are generated during the passage of the leading and trailing edges of the current pulse at the moment of maximum rate of change of the magnetic field, as shown in Figure 3. If the duration of the current pulse is 


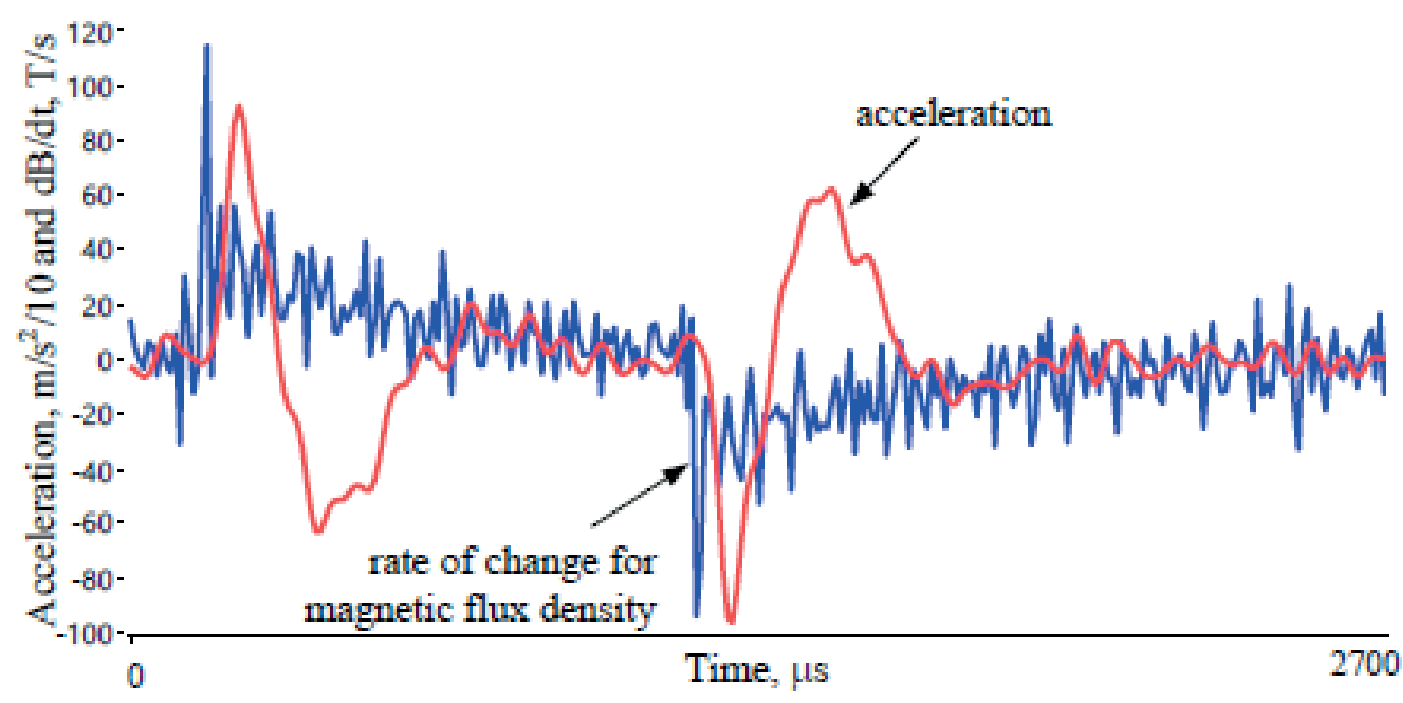

Figure 3: Radial vibration and the derivative of the magnetic induction for a sample of copper rod $\varnothing 3 \mathrm{~mm}$.

large enough, which is formed on the front and rear fronts of the damped mechanical oscillations are symmetric in nature, similar in amplitude and can be treated as an independent damped vibroacoustic shock processes. When reducing the duration of the current pulse, the rise of the amplitude of the magnitude of mechanical vibrations, as shown in Figure 4. The increase is due to the addition of the vibrations generated on the front and rear fronts of the current pulse.

The pulse duration of $100-150 \mu \mathrm{s}$, the fluctuation is because of the coincidence of the phases of these processes becomes maximal, with a further reduction in the duration there is a decrease in scope due to the mutual damping of the vibration oscillations [8]. Shown in Figure 4 according to different values of current flowing through the sample show that the dependence of the amplitude of oscillations of the amplitude of the current is close to linear.

As noted in the introduction, proposed a number of mechanisms which describe the transformation of energy of an electrical pulse passed through the sample in a mechanical deformation of the sample. This conversion finds practical application in electroplastic processing of metals, can be used when performing NDT.

According to [9] the possible mechanisms of electroplastic effect can't fully describe what happens in metallic specimens the processes of energy conversion of the current pulse into the energy of mechanical deformation. Among the proposed mechanisms are highlighted:

- thermofluctuational contribution from the wind quadratic in $\sigma$ and does not depend on the direction of the current; 


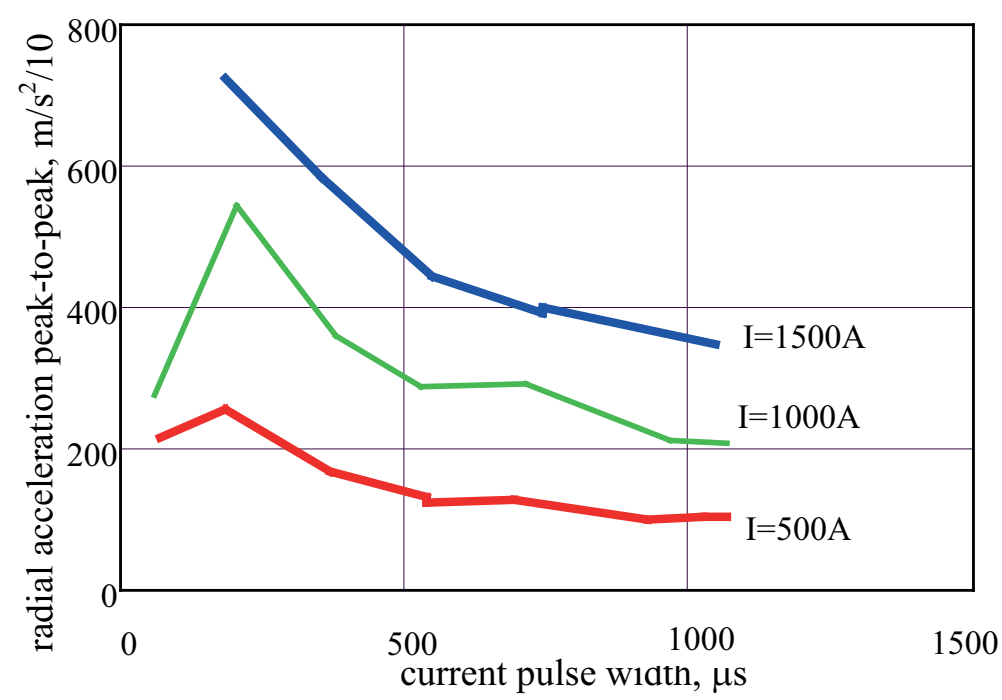

Figure 4: The dependence of the magnitude of the radial acceleration of the pulse current for a sample of copper of circular cross section with $\varnothing 3 \mathrm{~mm}$.

- mechanical stress near the surface (tangent to the surface) associated with the scattering of electrons near the surface. Such napryajeniya are polar in nature and is proportional to the current density;

- dynamic pinch-effect, delayed due to the influence of skin effect is delayed;

- dynamic temperature field - thermal stress. Considerably in size, but should give different effect on the front and rear fronts and is proportional to the pulse duration;

- the impact of current and magnetic field on the interaction of dislocations with point defects in metals;

- concept of dynamic equilibrium for the dislocation of the ensemble, the current pulse activates the internal voltage.

The complexity of the simultaneous action of electromagnetic high-frequency and low-frequency mechanical vibrations associated with changes in deformation complicates the interpretation of the obtained results, which is not possible with satisfactory precision to explain is often not only quantitatively but also qualitatively one of those mechanisms. It is difficult to understand the ongoing processes of elastic deformation of the samples under the action of pulsed current. Similar problems of analysis of the behavior of samples under the action of currents arise preblei high current densities when shown the plastic deformation and the difficulty of explaining the formation of strata at even higher current densities, a typical electrical explosion $[3,10,11]$. 


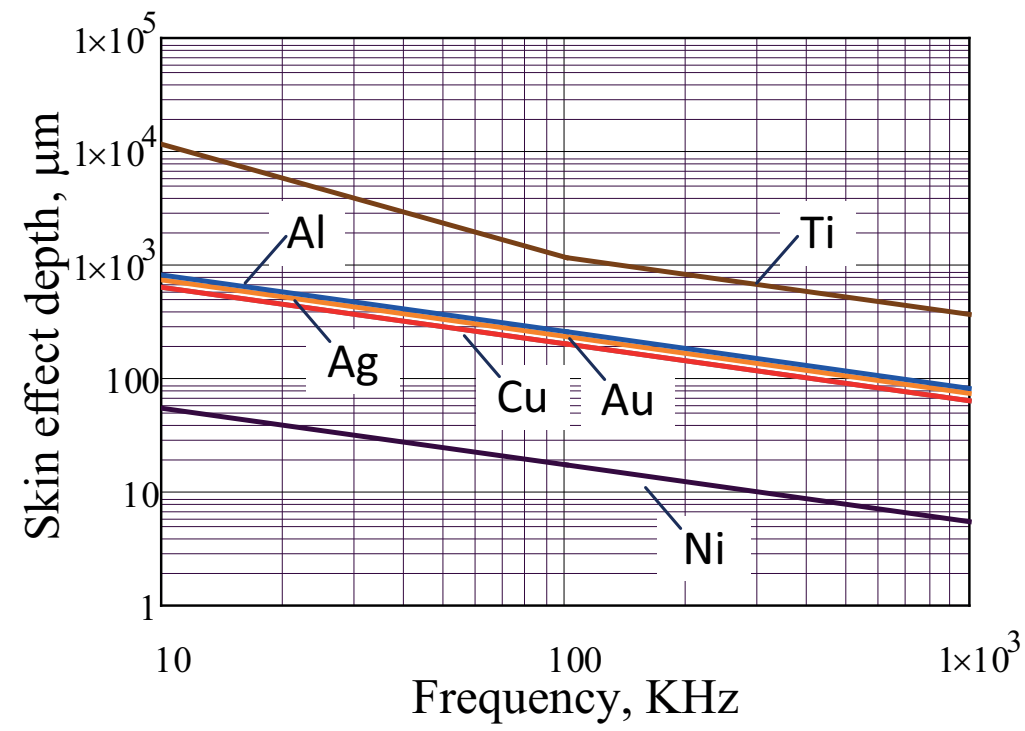

Figure 5: The dependence of the depth of the skin layer with frequency for different metals.

These mechanisms can add thermomechanical phenomena in surface skin layer, magnetohydrodynamic processes $[12,13]$, as well as the previously mentioned strengthening of the weak external signal fluctuations in a nonlinear system [5].

The short-term nature of the formation of deformation at the front of the pulse is the influence of the skin effect. The magnitude of the skin effect typically assess the depth of skin-layer, the dependence from frequency is shown in Figure 5. Some metals, such as titanium, can have the depth of the skin layer comparable to the thickness of the samples.The depth of the skin layer $\delta$ is determined by the ratio:

$$
\delta=\sqrt{\frac{1}{\mu \mu 0 \pi f \lambda}}
$$

where $\mu$ - relative magnetic permeability of the conductor material;

$$
\begin{aligned}
& \mu \mathrm{O}=1,257 \cdot 10^{-6} \mathrm{H} / \mathrm{m} ; \\
& f \text {-frequency; } \\
& \lambda \text { - conductivity. }
\end{aligned}
$$

Upon receipt of the momentum distribution of the current in the sample, there is practically no skin effect, as evidenced by the rapid growth of the current through the samples, measured the magnitude of the magnetic field. Metals are widely used as conductors (copper, silver), characterized by a thin skin layer and a relatively slow buildup of current through the sample. Despite these significant differences, the formation of vibroacoustic response to the passage of the current pulse has a similar 


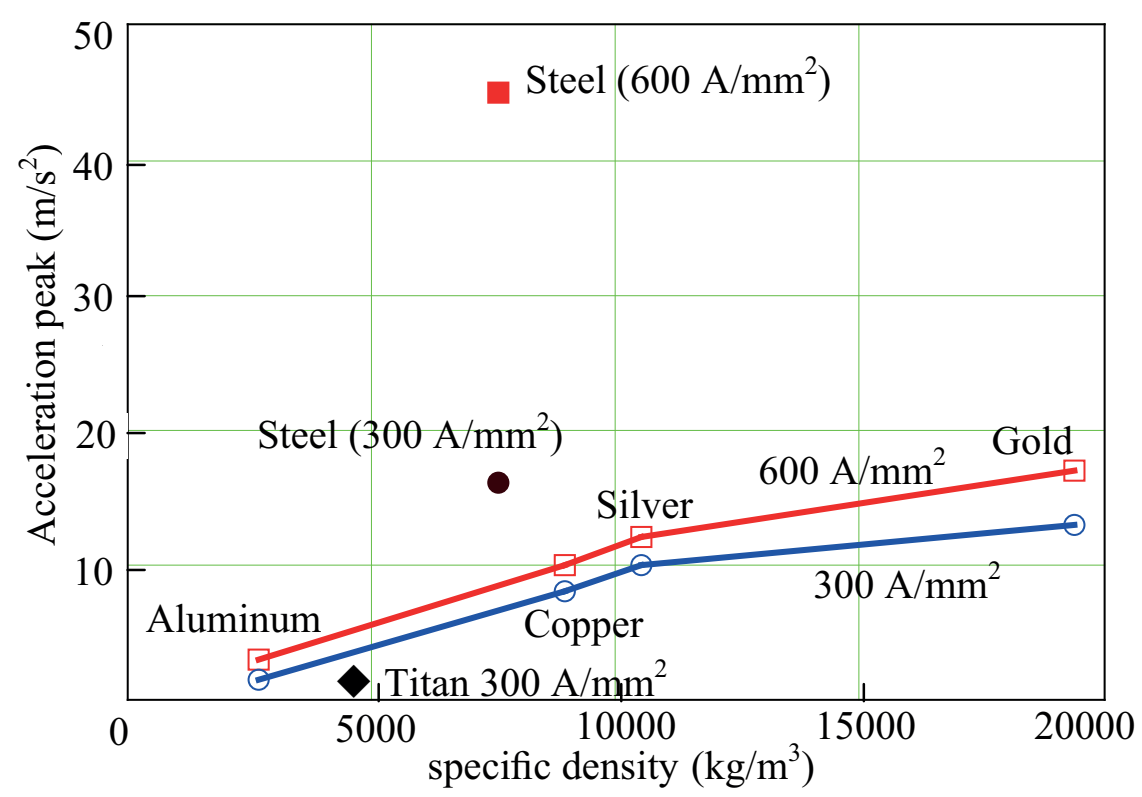

Figure 6: The amplitude of the radial acceleration for samples in the form of rods of circular cross section with $\varnothing 3 \mathrm{~mm}$ made of different metals.
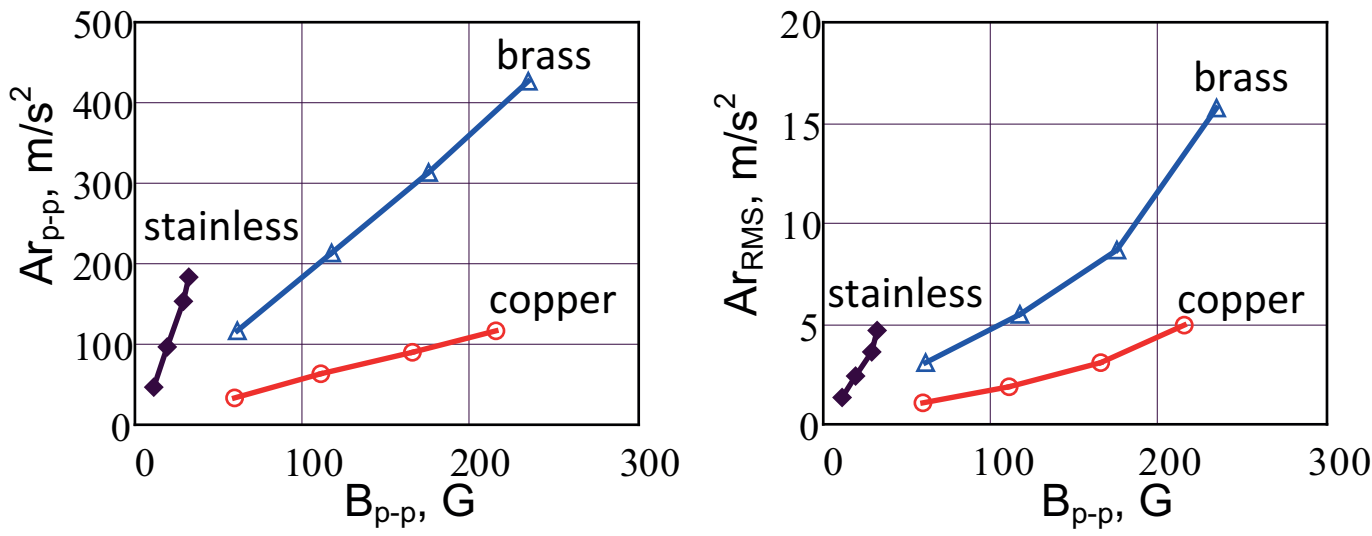

Figure 7: Based on the scale and was quadratic values of the radial component of the acceleration pulse magnitude value of magnetic induction.

character. The magnitude of the response in the form of estimates of maximum acceleration for samples of various metals are shown in Figure 6.

The dependence of the magnitude of the acceleration and the RMS values are shown in Figure 7. More resistant to the influence of noise rating on the scale shows an almost linear dependence on the magnitude of the magnitude of the magnetic induction corresponding to the magnitude of the current during the pulse.

Control of vibration and magnetic fields allows us to estimate the efficiency of energy conversion of an electric pulse to the magnetic field energy and into energy of mechanical vibrations. 
The energy of the electric pulse flowing through the sample is converted into heat Joule:

$$
Q=\int_{t s}^{t e} I^{2}(t) R d t
$$

Where $R$ is the resistance of the sample is calculated for the resistivity and dimensions of the sample for a given material; $t s$ - and te the start and end time of the current pulse; $I(t)$ is determined by measuring a calibrated gauge magnetic induction as a function of time.

The current is measured through magnetic induction by the relation:

$$
B=\frac{\mu \cdot \mu_{0}}{\pi} \cdot \frac{2 \cdot I}{r}
$$

where $\mu=1$ for non-ferromagnetic metals;

$r=0.07$ - distance sensor magnetic field from the sample;

$\mu 0=4 \cdot \pi \cdot 10^{-7} \mathrm{~T} \cdot \mathrm{m} / \mathrm{A}$.

Hence $I=B \cdot r / 8 \cdot 10^{-7}$.

The current pulse passing through the sample is converted to a magnetic field, which for the duration of the pulse accumulates energy $W$ of the magnetic field:

$$
W=\frac{L \int_{t s}^{t e} I^{2}(t) d t}{2(t e-t s)}
$$

where $L$ is the inductance of the sample. The inductance of a cylindrical sample [14] of length $/$ and radius $r$ :

$$
L=\frac{\mu 0}{2 \pi} l\left[\ln \left(\frac{2 l}{r}\right)-1\right]
$$

For the conductor of rectangular cross section expression similar, but instead of the radius from the geometric mean of the functions of the external dimensions of the sides of the transverse rectangular cross section.

The energy of mechanical vibrations of the specimen $E$ can be estimated by the ratio:

$$
E=\frac{M \int_{t s}^{t e^{\prime}} v^{2}(t) d t}{2\left(t e^{\prime}-t s\right)}
$$

where $M$ is the mass of the sample; $t e^{\prime}$ - the decay time of the oscillatory process in the sample induced by the pulsed current, to a level below the level of the vibration noise recorded by the vibration sensor; $v(t)$ - is the signal of the vibration velocity obtained from the vibration acceleration signals coming from the piezoelectric accelerometer using integration. 
Table 1 provides information about the characteristics of the three samples for which the dependence of vibration are shown in Figure 7.

TABLE 1

\begin{tabular}{|c|c|c|c|c|c|c|c|}
\hline Metal & $\begin{array}{l}\text { mass } \\
(\text { gram) }\end{array}$ & $R(\mathrm{mOm})$ & $L(\mathrm{nH})$ & $\delta(\mathrm{mm}$ & $Q(J)$ & $W(\mathrm{~mJ})$ & $E(\mu\rfloor)$ \\
\hline $\begin{array}{c}\text { stainless steel } 0,2 \times 4 \times 301= \\
280 A\end{array}$ & 0,173 & 4,5 & 26,03 & 1,38 & 0,314 & 1,02 & 159 \\
\hline copper $0,5 \times 3 \times 30 \mathrm{I}=2500 \mathrm{~A}$ & 0,402 & 0,342 & 24,13 & 0,2 & 1,919 & 75 & 2931 \\
\hline brass $0,5 \times 3 \times 30 \mathrm{I}=1700 \mathrm{~A}$ & 0,383 & 0,84 & 24,13 & 0,394 & 2,161 & 35 & 12290 \\
\hline
\end{tabular}

The relationship between heat energy, magnetic field energy and the energy of mechanical vibrations is presented as the "efficiency" of such transformations.

TABLE 2

\begin{tabular}{|c|c|c|c|}
\hline Metal & $\begin{array}{c}\text { efficiency factor } \\
(Q \Rightarrow W)\end{array}$ & $\begin{array}{c}\text { efficiency factor } \\
(W \Rightarrow E)\end{array}$ & $\begin{array}{c}\text { efficiency factor } \\
(Q \Rightarrow E)\end{array}$ \\
\hline stainless steel & $0,33 \%$ & $15,6 \%$ & $0,05 \%$ \\
\hline copper & $3,9 \%$ & $3,9 \%$ & $0,15 \%$ \\
\hline brass & $1,6 \%$ & $35 \%$ & $0,57 \%$ \\
\hline
\end{tabular}

\section{CONCLUSION}

Evaluation of energy conversion electrical pulse to the energy of deformation of the sample is essential to choose the mode of electroplastic processing. A significant range of variation of these coefficients does not allow us to predict the parameters of such processes. The data obtained on the formation of the damped oscillatory processes and the possibility of increasing the amplitude of the oscillations in the choice of pulse duration current provide the possibility of optimizing the choice of processing modes. To enable prediction of the behavior of samples with different geometric sizes from a variety of materials appropriate to continue the study of correlations between the processes of converting electrical impulses into mechanical strain.

\section{References}

[1] 0. A. Troitskiy, V. I. Stashenko, O. B. Skvortsov, Vliyaniye vibratsiy ot pinch-effekta impulsnogo toka na plasticheskuyu deformatsiyu, Actualscience, 2, № 2, 50-56, (2016). 
[2] V. V. Stolyarov, Deformatsionnoye povedeniye nanokristallicheskikh i amorfnykh splavov pri rastyazhenii s tokom, VNTR, № 10, 44-50, (2015).

[3] A. L. Surkayev, Informatsionno-izmeritelnaya sistema dlya izmereniy parametrov sinteziruyemykh tekhnologiy na osnove elektricheskogo vzryva provodnikov, Dissertatsiya na soiskaniye uchenoy stepeni doktora tekhnicheskikh nauk, Volgograd, 267 S., (2016).

[4] I. L. Bataronov, Mekhanizmy vliyaniya elektricheskogo polya i elektricheskogo toka na plasticheskuyu deformatsiyu metallov, Dissertatsiya na soiskaniye uchenoy stepeni doktora tekhnicheskikh nauk, Voronezh, 280 s., (2010).

[5] P. P. Kaminskiy, Yu. A. Khon, E. V. Tuch, O mekhanizmakh vliyaniya elektricheskogo polya na plasticheskuyu deformatsiyu provodnikov, Sbornik tezisov dokladov 54 Mezhdunarodnoy konferentsii "Aktualnyye problemy prochnosti», Ekaterinburg, 131, (2013).

[6] 0. A. Troitskiy, O. B. Skvortsov, V. I. Stashenko, Generation of mechanical vibrations in metal samples by the use of the pinch effect, IOP Conference Series: Materials Science and Engineering, 218, 1-6, (2017).

[7] O. B. Skvorcov, Differencial'nye izmereniya trekhmernyh fizicheskih velichin Sbornik trudov konferencii NI Academic Days 2017, M.: Izd-vo "Pechatnye centry FAN", 104107, (2017).

[8] 0. A. Troickij, V. I. Stashenko, O. B. Skvorcov, E. A. Pravotorova, Dinamicheskoe vozbuzhdenie kolebanij v metallicheskih provodnikah pri propuskanii impul'snyh tokov Sovremennye tendencii razvitiya nauki i tekhnologij, № 1-1, 137-139, (2017).

[9] I. L. Bataronov, Mekhanizmy ehlektroplastichnosti, Sorosovskij obrazovatel'nyj zhurnal, № 10, 93-99, (1999).

[10] J. Nasilovski, Exploding wires, ed. W.G. Chase and H.K. Moore, (New York: Plenum), 3, 295-299, (1964)

[11] V. I. Oreshkin, K. V. Khishchenko, P. R. Levashov, A. G. Rousskikh, S. A. Chaikovskii, strata formation at fast electrical explosion of cylindrical conductors, High Temperature, 50, No. 5, 584-595, (2012).

[12] A. Surkaev, Magnetohydrodynamic Perturbations Arising in Metallic Conductors under the Action of the Discharge Current, Technical Physics, 60, № 7, 981-985, (2015).

[13] A. S. Skal, The full Lorentz force formula reposible for turbulence in solids and fluids and explained Faraday's paradox, International Journal of Scientific \& Engineering Research, 4, № 2, 10-16, (2013). 
[14] P. L. Kalantarov, L. A. Cejtlin, Raschet induktivnostej: Spravochnaya kniga, 3-e izd., L., EHnergoatomizdat, $488 \mathrm{~s}$, (1986). 